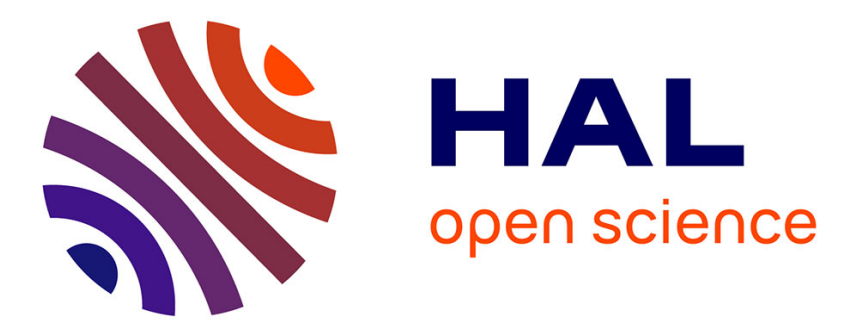

\title{
Effect of loading mode on blistering in iron submitted to plastic prestrain before hydrogen cathodic charging
}

S. Ayadi, Y. Charles, M. Gaspérini, I. Caron Lemaire, Tony da Silva Botelho

\section{To cite this version:}

S. Ayadi, Y. Charles, M. Gaspérini, I. Caron Lemaire, Tony da Silva Botelho. Effect of loading mode on blistering in iron submitted to plastic prestrain before hydrogen cathodic charging. International Journal of Hydrogen Energy, 2017, 42 (15), pp.10555 - 10567. 10.1016/j.ijhydene.2017.02.048 . hal01538829

\section{HAL Id: hal-01538829 \\ https://hal.science/hal-01538829}

Submitted on 15 Jul 2019

HAL is a multi-disciplinary open access archive for the deposit and dissemination of scientific research documents, whether they are published or not. The documents may come from teaching and research institutions in France or abroad, or from public or private research centers.
L'archive ouverte pluridisciplinaire HAL, est destinée au dépôt et à la diffusion de documents scientifiques de niveau recherche, publiés ou non, émanant des établissements d'enseignement et de recherche français ou étrangers, des laboratoires publics ou privés. 


\title{
Effect of loading mode on blistering in iron submitted to plastic prestrain before hydrogen cathodic charging
}

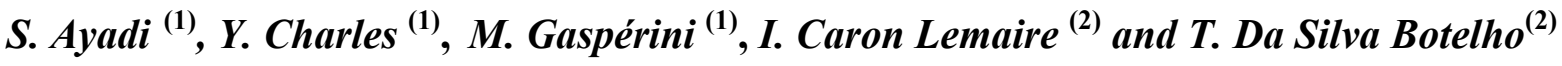 \\ (1) Université Paris 13, Sorbonne Paris Cité, Laboratoire des Sciences des Procédés et des Matériaux, LSPM, CNRS, \\ UPR 3407, 99 avenue Jean-Baptiste Clément, F-93430 Villetaneuse, France \\ ${ }^{(2)}$ Supméca, Laboratoire QUARTZ (EA 7393), 3 rue Fernand Hainaut F-93407 Saint Ouen Cedex
}

\begin{abstract}
Tensile tests and simple shear tests have been performed on Armco iron sheets before hydrogen cathodic charging, in order to study the effect of loading mode on blistering of plastically prestrained samples. The experimental results from surfometry and image analysis show the decrease of the blisters size with prestrain increase, and quantitative differences between tensile or shear prestrain are exhibited. Phenomenological modeling of blister initiation is proposed, based on void expansion increase under internal pressure, and considering both plastic strain and pores as traps during hydrogen transport. Finite element simulations of material expansion due to hydrogen induced void growth lead to qualitative agreement with experimental tendencies.
\end{abstract}

Keywords: hydrogen; blisters; iron; plasticity; prestrain; finite element

\section{Introduction}

Hydrogen embrittlement (HE) is a severe risk of failure for metallic materials and is studied from decades, especially in iron and steel, as can be found in classical reviews [1, 2]. For industrial purposes, the selection and the design of materials insensitive to hydrogen is an important challenge for safety of applications linked to transport and hydrogen storage [3]. For academic research, the understanding of the role of hydrogen in materials is particularly stimulating and many questions remain open due to the complexity of hydrogen-material interactions and to the different involved scales from the electronic configuration at the atomic scale $[4,5]$ to the failure of macroscopic structures [6]. Between the two, the microstructural defects such as solutes, precipitates [7], vacancies [4, 8], dislocations [9], grain boundaries [10] are evocated in hydrogen induced cracking, and efforts have been performed to model hydrogen-material interactions and cracking at different scales [11, 12]. In case of local hydrogen or vacancies supersaturation, without achievement of hydride formation, hydrogen assisted growth of cavities may lead to bubbles or blister formation, as reviewed by Condon and Schober [13]. These authors defined blisters as a void or a bubble close to the sample surface, usually observable by SEM or optical microscopy. Hydrogen induced blistering can be seen as a special case of the plane pressure mechanism of hydrogen embrittlement, where high pressure hydrogen forms in microvoids near the material's surface [14]. It is encountered in various materials, such as Al and Mo [15], Ni-P amorphous alloys 
[16] and pipelines steels in sour environment [17]. Blistering is also encountered in ferriticmartensitic steels after exposition to hydrogen plasma, where both irradiation and cold work influence the occurrence and distribution of blisters [18]. Owing to the variety of microstructures and of conditions leading to blisters, focus on single phase materials is necessary to more precisely investigate the phenomena. Detailed investigation of blisters were performed in pure iron $[14,19,20]$, which is used as a reference material to focus on for HE analysis in steels. Optical or SEM microscopy were used for characterization of blisters and related subsurface associated cracks. Recent observations [14] by 3D neutron tomography on an Armco $\mathbb{C}$ iron has clearly established the presence of hydrogen inside or around the formed cracks, which was consistent with the blistering mechanism proposed by Ren et al [20]. These authors suggested superabundant vacancies and hydrogen aggregation into a hydrogenvacancy cluster to be responsible for the blister nucleus, followed by blister growth up to a critical size leading to crack initiation from the wall of the cavity. Crack and blister initiation and growth in purified iron was recently investigated, at the SEM and TEM scale, pointing out the importance of local plasticity [21]. Escobar et al [19], furthermore, showed pure iron was more prone to blistering than high strength steels in which the so-called internal cracking at mid-thickness of the sheet was the salient feature. Cracking and blistering was also found microstructure-dependent in a X70 steel [22]. Strengthening mechanisms appear then to influence hydrogen induced cracking and blistering, but further analysis from these works is limited due to the differences in materials composition and microstructure. Plastic strain is known to affect the hydrogen diffusivity in iron [10] because of trapping [23] and/or dislocations transport [24] but reported works on blisters in pure iron mainly concern annealed material $[14,19-21]$. Then the effect of strain-hardening on these phenomena remains an open question.

In this context, the present study aims at investigating hydrogen induced cracking and blistering in pure iron, with a special attention on the effect of plastic strain before hydrogen charging. Cathodic charging is performed on Armco(C) iron sheet samples, and resulting hydrogen-induced damage is compared for non-deformed and prestrained samples. To analyze the influence of the deformation mode and of the strain range, tensile tests and simple shear tests are considered, as a first step towards complex loading modes encountered in sheet metal forming. Quantitative data on blisters size are obtained, and the experimental tendencies are discussed with the help of finite element simulations using a phenomenological model for blistering initiation based on void expansion increase under internal pressure, and considering both plastic strain and pores as traps during hydrogen transport.

\section{Experimental procedure}

Armco iron supplied as annealed rolled plates of $1 \mathrm{~mm}$ thickness, considered as the initial reference (IR) is used for the study. The chemical composition of the material is given on Table 1.

Table 1. Chemical composition of the iron material (in wt. \%). 


\begin{tabular}{cccccccc}
$\mathrm{Fe}$ & $\mathrm{C}$ & $\mathrm{Mn}$ & $\mathrm{P}$ & $\mathrm{S}$ & $\mathrm{N}$ & $\mathrm{Cu}$ & $\mathrm{Sn}$ \\
\hline$>99.8$ & 0.010 & 0.100 & 0.010 & 0.008 & 0.006 & 0.030 & 0.010
\end{tabular}

Samples for cathodic charging and for mechanical tests along the rolling direction (RD) of the sheet were cut off from the sheet by spark-machining.

Uniaxial tensile tests and simple shear tests were performed with a conventional electromechanical tensile machine, using an equivalent strain rate $\&=10^{-4} \mathrm{~s}^{-1}$.

Von Mises equivalent strain $\bar{\varepsilon}$ was used to compare tensile and shear strain values. Assuming isotropic rigid-plastic material behavior (the elastic strain being negligible compared to the plastic strain in the considered strain range) and von Mises plastic potential with isotropic hardening, the equivalent cumulated plastic strain for a proportional loading up to final strain tensor $\varepsilon^{\mathrm{p}}$ is $\bar{\varepsilon}=\sqrt{\frac{2}{3} \sum_{\mathrm{i}, \mathrm{j}} \varepsilon_{\mathrm{ij}}^{\mathrm{p}} \varepsilon_{\mathrm{ij}}^{\mathrm{p}}}$. For tensile tests with axial strain $\varepsilon$ and transverse strains $-\varepsilon / 2$ (as plastic volumetric strain is zero), $\bar{\varepsilon}=\varepsilon$. For shear tests (say in plane $(1,2)$, the only non-zero components are $\varepsilon_{12}^{\mathrm{p}}=\varepsilon_{21}^{\mathrm{p}}=\gamma / 2$, therefore $\bar{\varepsilon}=\gamma / \sqrt{3}$ where $\gamma$ is the shear strain.

The samples geometries are shown in Fig. 1.

Simple shear tests were made with a house-made device mounted on the tensile machine [25]. Parallelepiped samples $30 \mathrm{~mm}$ long, $18 \mathrm{~mm}$ width and $1 \mathrm{~mm}$ thick were used, the dimensions of the shear zone being $30 \times 2 \times 1 \mathrm{~mm}^{3}$. This geometry choice ensures a good strain homogeneity in the sheared zone, as resulting from previous studies using finite element simulations of the test $[25,26]$ to minimize inherent strain inhomogeneity due to the sample free ends effects. The simple shear test is controlled by video-extensometry with a CDD camera: the sample surface is first painted in white, and then a black line is drawn perpendicularly to the shearing direction. The optical device determines on-line the slope of the black line, by best fit of the white-to-black transitions determined on the pixel lines parallel to the shearing direction. The evolution of this slope is used both for computing the amount of shear $\gamma$ and to monitor the shear strain rate during the test.

The present tests were conducted up to $\gamma=20 \%, 30 \%, 50 \%$ or $90 \%,(\gamma=\tan (\theta)$ in Fig. $1 \mathrm{~b})$, leading to $\bar{\varepsilon}=11.5 \%, 17.3 \%, 28.8 \%$ and $52 \%$ respectively. The corresponding samples were hereafter referred as S11, S17, S28, S52 respectively.

Tensile tests were performed on dog-bone samples (ensuring overall strain homogeneity in the gauge length) with $80 \mathrm{~mm}$ gauge length and $12.2 \mathrm{~mm}$ width up to final true strain values $\varepsilon=11 \%$ and $\varepsilon=26 \%$, hereafter referred as $\mathrm{T} 11$ and T26 samples respectively. The true strain $\varepsilon$ was computed from the measurement of a clip-on extensometer with $\mathrm{L}_{0}=10 \mathrm{~mm}$ gauge length: from the displacement $\Delta \mathrm{L}$ measured by the extensometer, the true strain was $\ln \left(1+\Delta \mathrm{L} / \mathrm{L}_{0}\right)$.

The $\bar{\varepsilon}$ values are similar for T11 and S11 samples, and very close for S28 and T26 ( $\varepsilon=28 \%$ was not attainable because of necking initiation). 


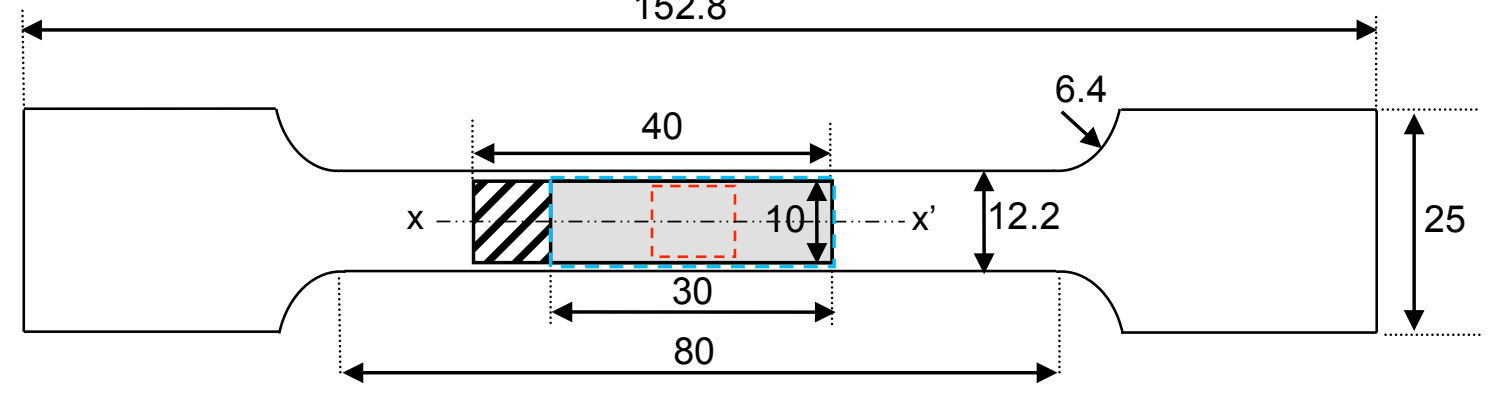

(a)

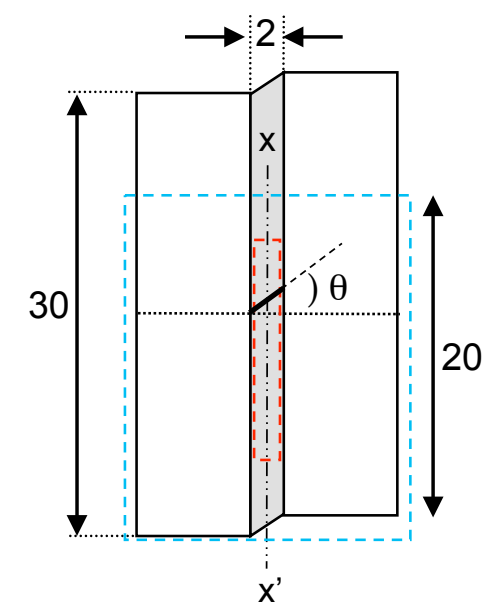

(b)

Fig. 1. Samples geometry for (a) tensile test and (b) simple shear test (the sheared zone is grey-colored, and $\gamma=\tan (\theta))$. The dimensions are in $\mathrm{mm}$. The blue dashes indicate the zones submitted to cathodic charging after the mechanical tests (in (a) the area hatched in black corresponds to sample holding). Inside these zones, the red dashes indicate the zones for blisters investigation by surfometry and SEM, and the $\mathrm{xx}^{\prime}$ ' lines indicate the sections for through thickness investigations.

The Fig. 2 shows the true stress-strain curves for tensile and shear tests. The stress variations at the beginning of the curves are due to the Lüders band phenomenon. The homogenous strain values obtained by shear test are about twice larger compared with tensile test. 


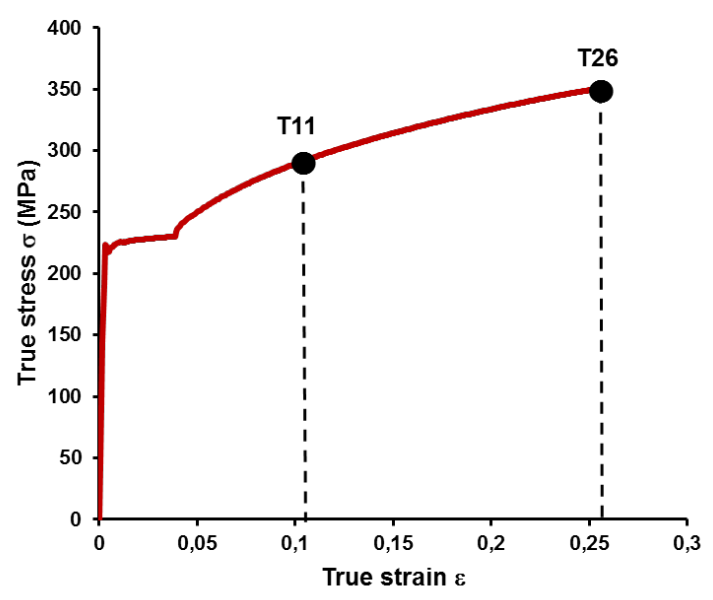

(a)

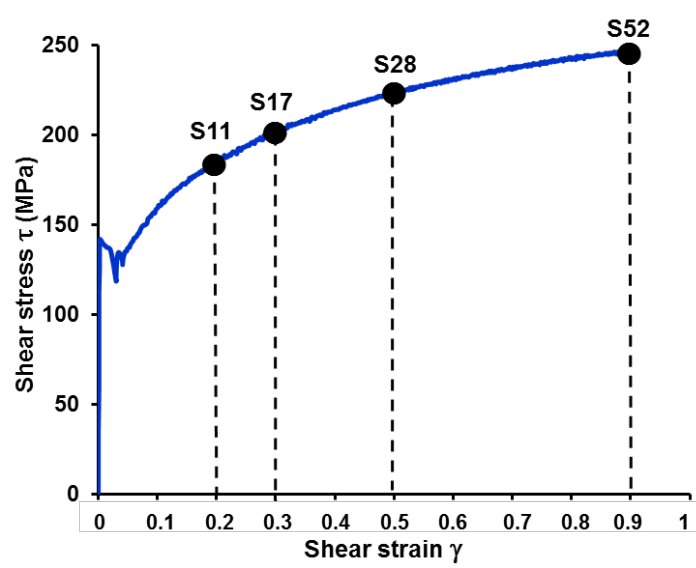

(b)

Fig. 2. Stress-strain curves of Armco iron during (a) uniaxial tensile tests and (b) simple shear tests. The dots indicate the strain values considered before cathodic charging.

All deformed samples were submitted to cathodic charging, as well as a non-deformed sample (I-H). $40 \mathrm{~mm}$ long, $10 \mathrm{~mm}$ wide parallelepiped samples were cut in the initial sheet and in the tensile samples after deformation, whereas the full samples were used after shear tests (see Fig. 1). Owing to the samples holding, the dimensions of the zone submitted to the electrolyte was $30 \times 10 \times 1 \mathrm{~mm}^{3}$ for the initial and tensile samples, and $20 \times 18 \times 1 \mathrm{~mm}^{3}$ for the sheared samples. The samples were carefully polished before hydrogen charging. Mechanical polishing with 1200 to 4000 grit paper then electropolished with A2 electrolyte from Struers at $40 \mathrm{~V}$ for $12 \mathrm{~s}$. Finally the samples were cleaned into an ultrasound bath, washed with ethanol and dried with hot air.

Hydrogen was introduced in the samples by cathodic charging at room temperature in an aqueous solution of $1 \mathrm{M} \mathrm{H}_{2} \mathrm{SO}_{4}$ electrolyte with $0.5 \mathrm{~g} / \mathrm{l}$ of $\mathrm{As}_{2} \mathrm{O}_{3}$. As used by several authors $[14,19] \mathrm{As}_{2} \mathrm{O}_{3}$ was added to the electrolyte in order to promote hydrogen atom absorption into the metal (instead of hydrogen molecular recombination). 
In the electrochemical cell the sample was parallel to a platinum electrode $\mathrm{Pt}$, at a distance of $20 \mathrm{~mm}$, the length of the immersed area was $30 \mathrm{~mm}$ for initial and tensile samples, and 20 $\mathrm{mm}$ for shear samples. The samples were charged during $24 \mathrm{~h}$ at a current density of $10 \mathrm{~mA} / \mathrm{cm}^{2}$. After charging, samples were cleaned with acetone and ethanol to eliminate possible surface layer.

After hydrogen charging, macroscopic characterization of blistering was made by mechanical surfometry with SOMICRONIC Surfascan 3S. Surface scans with $8 \mu \mathrm{m}$ step were performed on surfaces with typical size $64 \mathrm{~mm}^{2}$ for tensile samples and $16 \mathrm{~mm}^{2}$ for shear samples. Surface topographies were analyzed using Mountains Maps software. The scan step was chosen for compromise between precise measurement on large areas and time consumption.

Observations on a FEG-SEM were made on the sample surface (RD, TD) and on longitudinal (RD,ND) sections. Systematic observation of (RD,ND) sections with $20 \times 1 \mathrm{~mm}^{2}$ size was performed for quantitative image analysis of cracked areas with ImageJ software. Manual adjustment of image contrast was made before binarisation, then the crack features were automatically deduced from the software for subsequent analysis.

\section{Results}

\subsection{Quantitative analysis of blisters on the samples surface}

To distinct blister topography from natural roughness features, a threshold altitude was defined on surfaces prior to hydrogenation. The selected threshold value (measured from the deepest valley) was the standard roughness parameter Sz, defined as the vertical distance between the highest asperity and the deepest valley of a surface [27]. As a result, only the blisters exceeding the threshold were detected and analyzed.

The remaining blisters were quantitatively analyzed. Each blister is considered as a single asperity and classical grain-count tools were used, giving heights, equivalent diameters and cumulative surfaces statistics.

Fig. 3 shows typical relief mappings extracted from the contact surfometry of the samples surfaces. Initial Sz roughness parameter of the non-charged and non-deformed sample (I-0) was $3.8 \mu \mathrm{m} \pm 0.7 \mu \mathrm{m}$ (Fig. 3a). As seen with the naked eye, huge blistering is evidenced after cathodic charging and is more important in non-deformed sample (Fig. 3b) than in deformed samples, as illustrated in Fig. 3c for sample T26. 


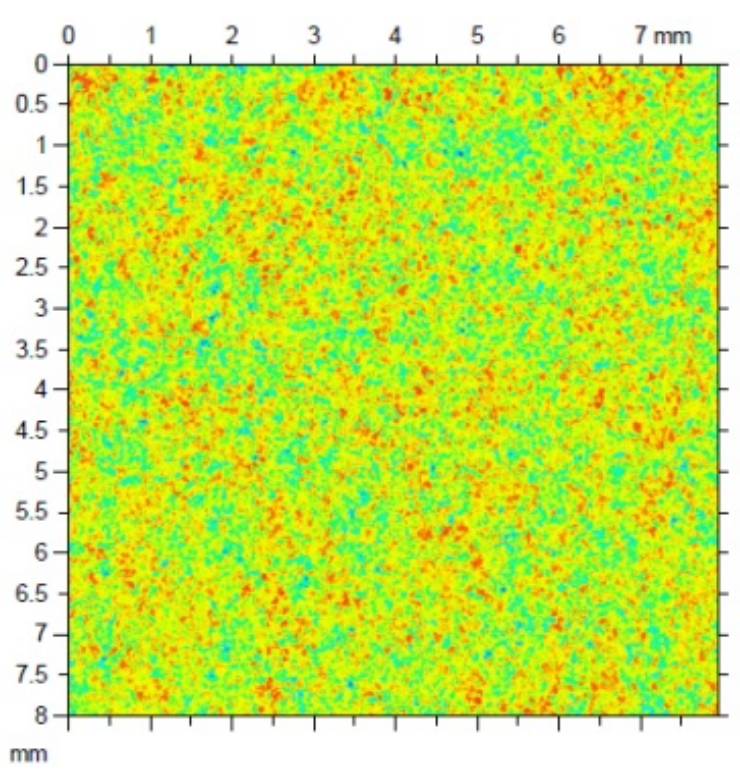

Height $(\mu \mathrm{m})$

(a)

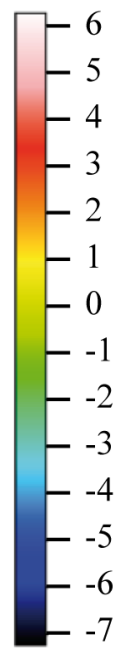

Height $(\mu \mathrm{m})$
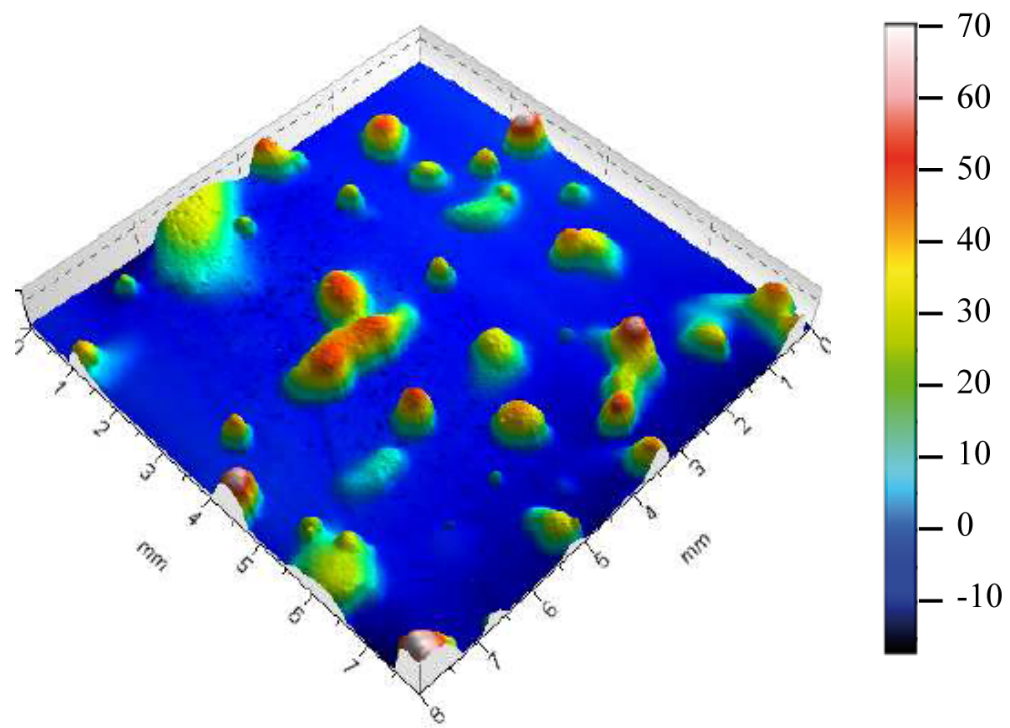

(b)

Height $(\mu \mathrm{m})$
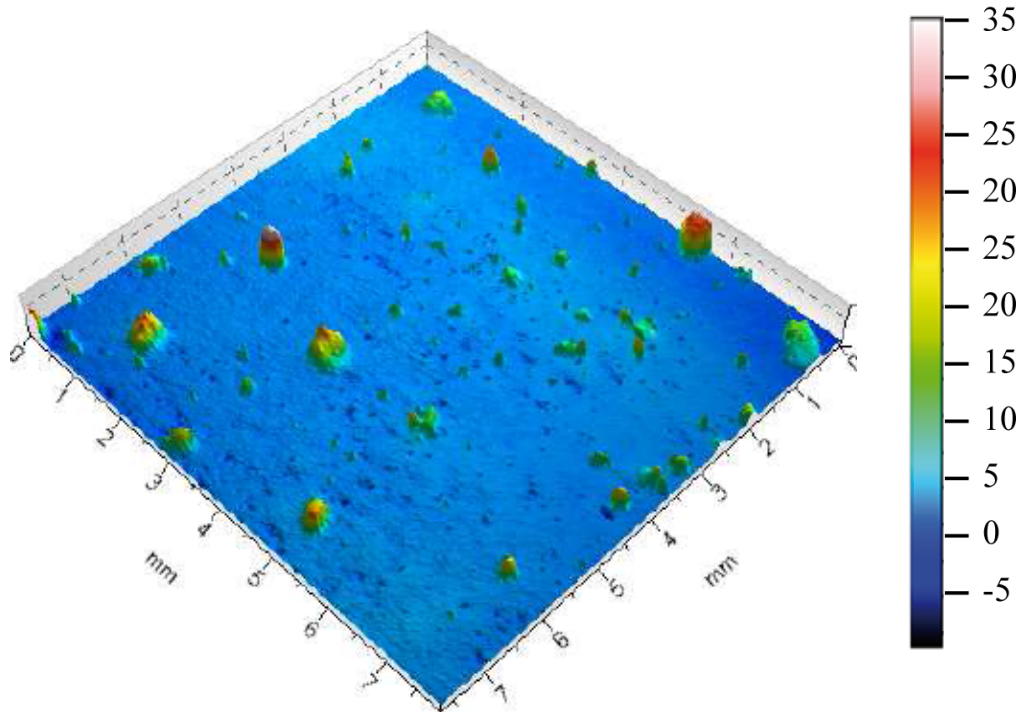

(c)

Fig. 3. Height maps from surfometry measurements on (a) IR, (b) I-H and (c) T26 samples. 


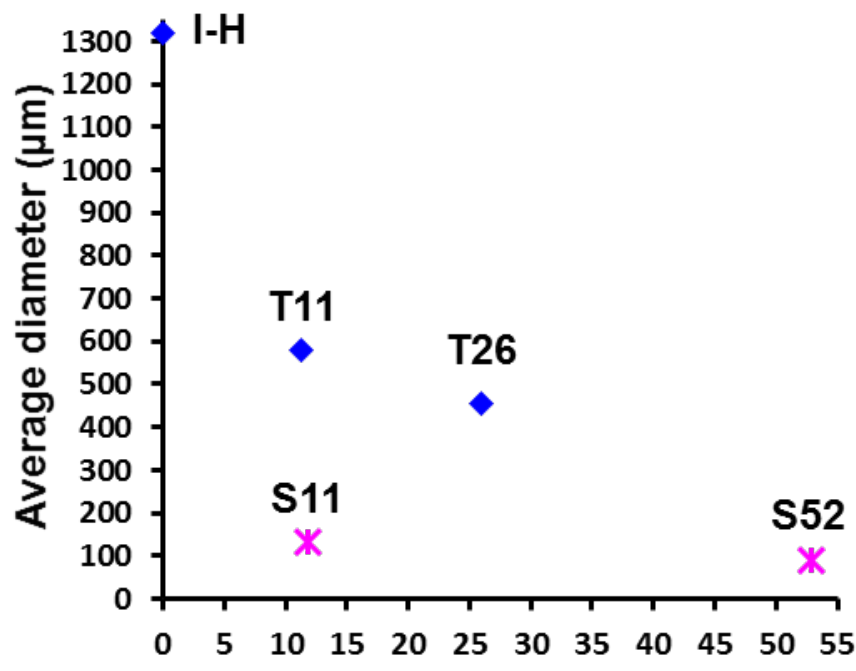

Equivalent plastic strain (\%)

(a)

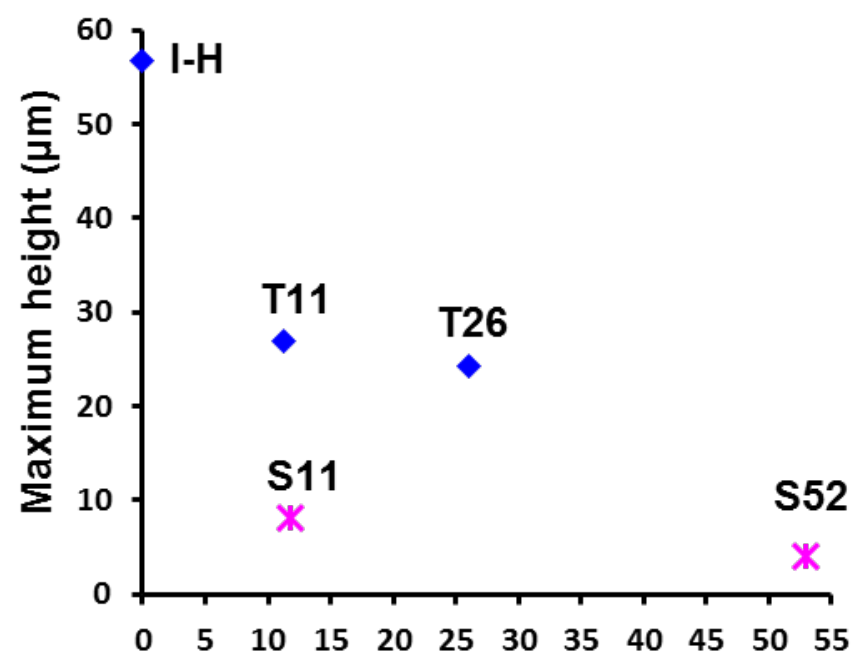

Equivalent plastic strain (\%)

(b) 


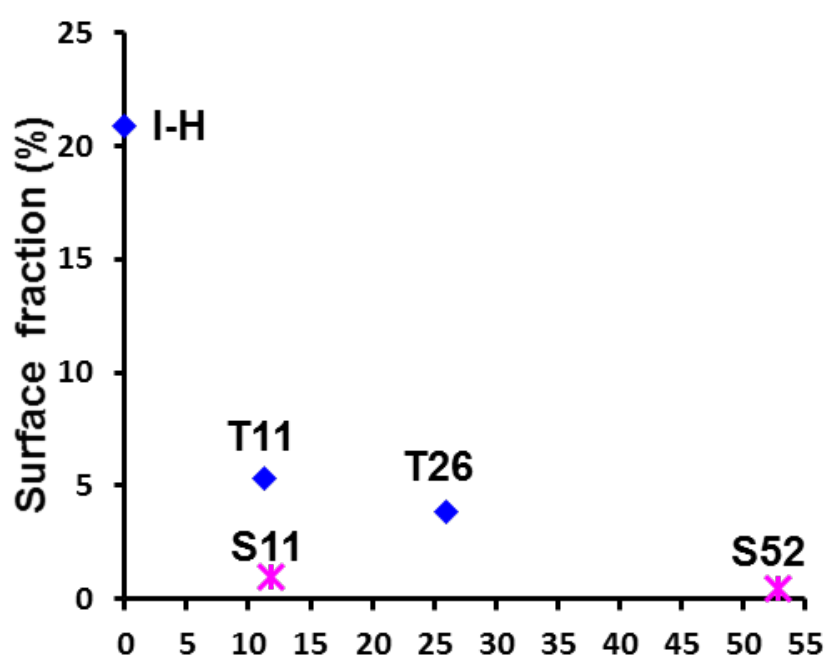

\section{Equivalent plastic strain (\%)}

(c)

Fig. 4. Evolution of (a) mean diameter, (b) maximum height and (c) surface fraction of blisters with plastic strain.

The main quantitative features of blisters and their evolution with plastic prestrain are given in Fig. 4. For all samples, surfaces topographies after hydrogen charging are strongly different compared to the initial surfaces, due to the apparition of blisters.

As shown in Fig. 4, the average diameter, the maximum height of blisters and their surface fraction significantly decrease with plastic strain whether with tensile or shear solicitations. In the reference I-H sample, the blister diameter $(1300 \mu \mathrm{m})$, maximum height $(58 \mu \mathrm{m})$ and surface fraction $(21 \%)$ are clearly higher than in deformed samples. When plastic strain is applied, the mean diameter and the maximum height for the most deformed sample (S52) are roughly ten times lower than the non-deformed sample (I-H). The decrease of all the three parameters, however, is non-linear. A strong effect of plastic strain on the dimensions of the blisters is then exhibited, especially at low plastic strain. It is worth noting that despite somewhat less good statistic due to the smaller gauge length size in shear, the blisters size after shear is significantly smaller than after tension. In particular, for the same equivalent plastic strain $\varepsilon=11 \%$, the mean blister diameter (Fig. 4a) and the maximum blister height (Fig. 4b) are more than three times larger after tension than shear. The deformation mode, leading to different dislocation patterning, seems then to influence the blistering phenomenon. More detailed observations of blisters and cracks on a finer scale by SEM are reported below. 
3.2. SEM analysis of blisters and cracks

\subsubsection{Observations of blisters on (RD, TD) surface}

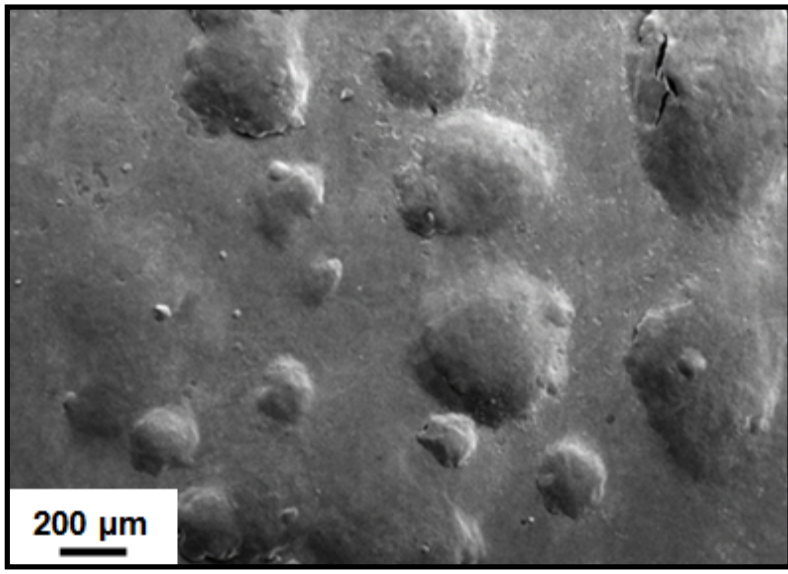

(a)

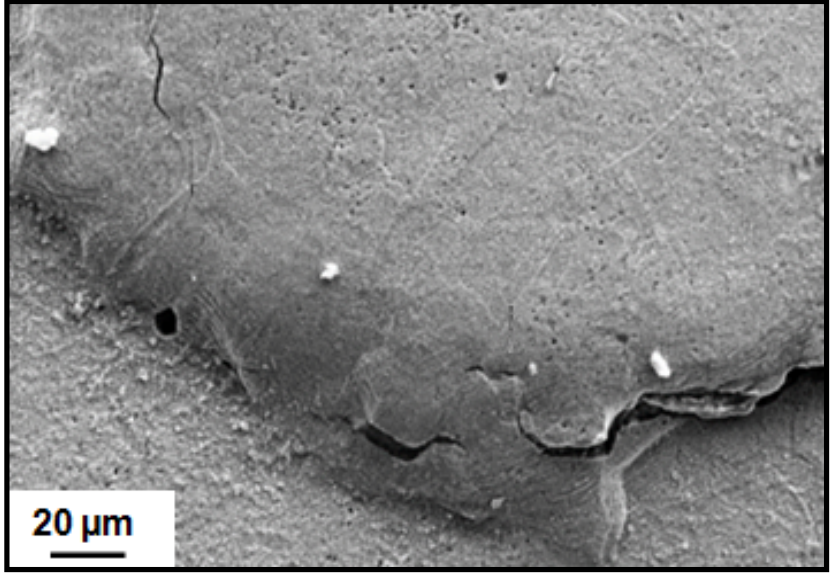

(b)

Fig. 5. (a) General aspect on blisters on the I-H sample, and (b) of a large flat blister on S52 sample.

Fig. 5a shows the typical aspect of blisters seen by SEM at moderate magnification. In addition to large blisters extending upon several tens microns already evidenced by surfometry (Fig. 3b), which are flatter in sheared samples (Fig. 5b), many small blisters are also present, some of them superimposed on the larger ones. Slip lines accompanying plastic strain during the blistering formation are seen at higher magnification (Fig. 6a). Some blisters are cracked, the cracks being preferentially located on the blister slopes. A detailed view of a cracked blister is shown on Fig. 6b, with magnification of the brittle like fracture surface, denoting hydrogen embrittlement process. Several pores are seen on this surface, as already noticed by other authors [14]. The main blister features are common for non-deformed and deformed samples. In particular, slip lines evoking plastic expansion during bulging formation are visible at the blister surface in both cases at the micron scale. Small blister may be inside one grain or concern several grains, as illustrated by Fig. 6a, where slip lines on the blister are partly stopped on a grain boundary.

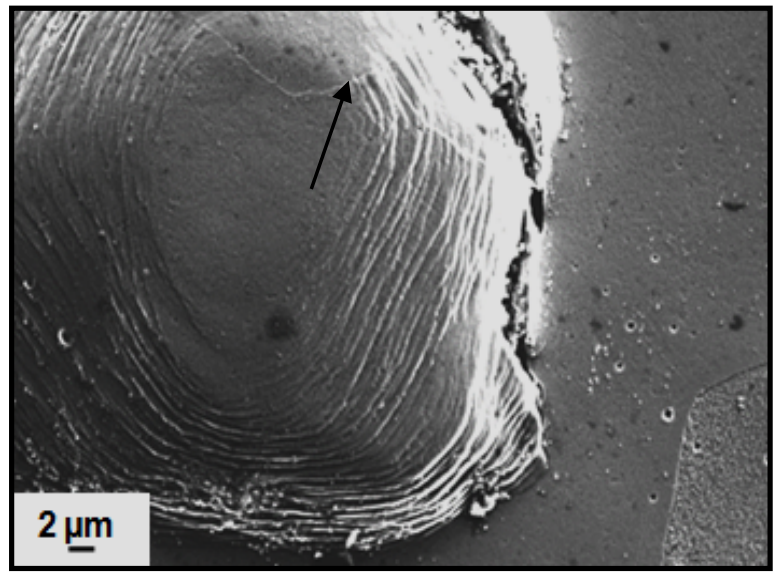

(a)

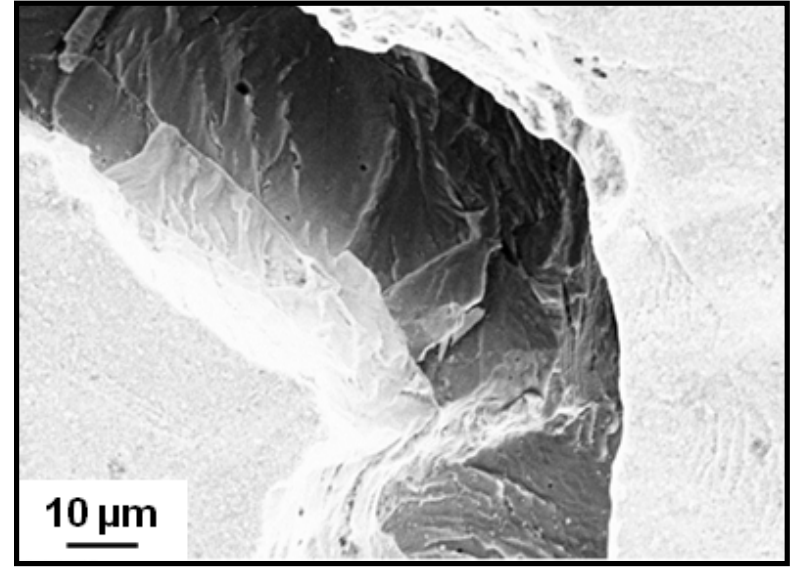

(b)

Fig. 6. (a) Slip lines on blisters on T26 sample. The arrow indicates slip lines stopping at a grain boundary; (b) cracked surface of a blister. 


\subsubsection{Cracks analysis in (RD,ND) section}

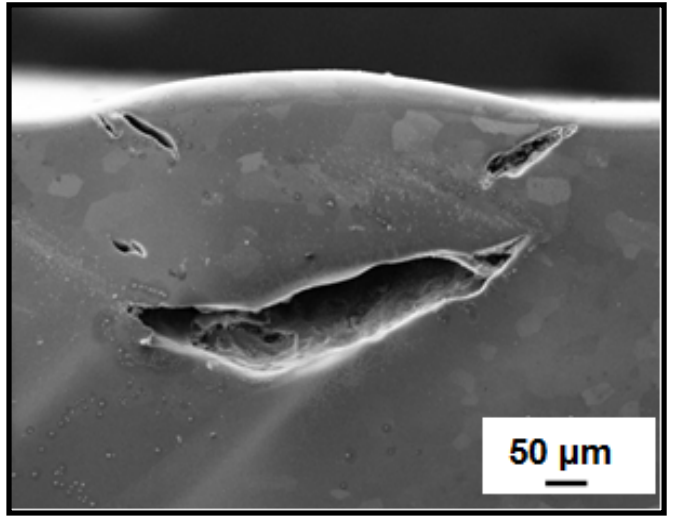

(a)

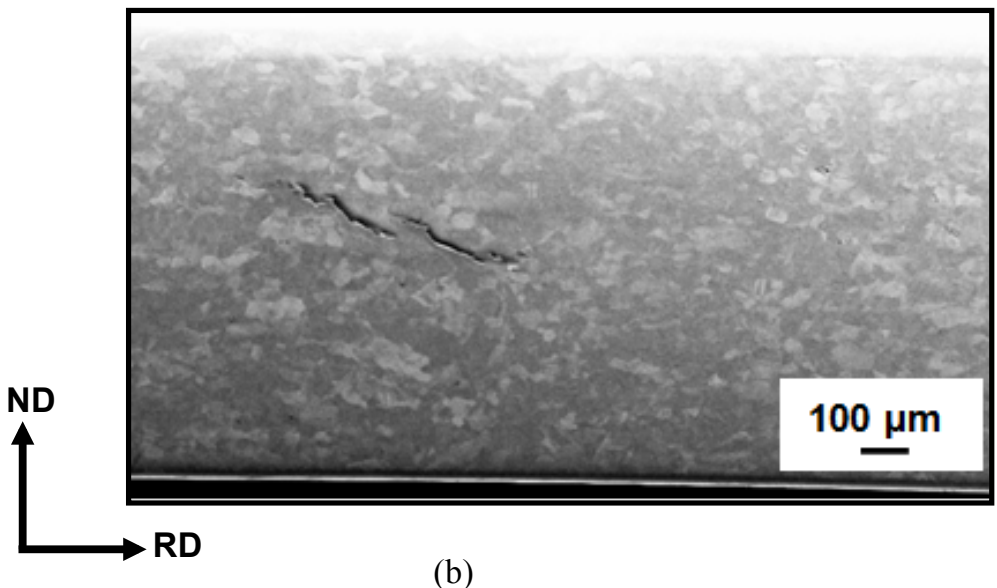

(b)

Fig. 7. SEM images of cracks in the (RD, ND) section of (a) I-H and (b) S52 samples.

Fig. 7 shows typical aspects of hydrogen-induced cracks in (RD, ND) sections of the samples. In non-deformed sample (Fig. 7a), large curvilinear cracks with high opening displacement are seen below the blisters observed on the surface. In tensile deformed samples, these type of cracks are less numerous and smaller. The through thickness extent of the damage due to these cracks tends to decrease with increasing strain. Meanwhile, some rare grain-size cracks are found at mid-thickness. In the samples prestrained by shear, both types of cracks are found after moderate plastic strain, but for highly strained samples, internal cracks at mid-thickness are predominant and may be significantly longer than the grain size (Fig. 7b). These cracks appear straighter than those found under prominent blisters at the sample surface.

The Fig. 8 shows the results of the quantitative analysis of SEM pictures with ImageJ software on sections with dimensions $20 \times 1 \mathrm{~mm}^{2}$ for the different samples. For each crack, the width was measured (manually, with the help of standard tools for image analysis) perpendicularly to the crack lips, at the point of maximum opening. The surface crack density (Fig. 8a) and the mean crack opening (Fig. 8b) are presented as function of the equivalent plastic strain before hydrogen charging. The surface density occupied by cracks under the blisters clearly decreases with plastic strain (Fig. 8a), mainly due to smaller crack-opening for deformed samples (Fig. 8b) and to lower blister size, this evolution being similar for either tensile or shear prestrain. Mid-thickness internal cracks are significant on shear samples after large strain, and are less open than the blister cracks. It can be noticed that the presence of these cracks (Fig. 8b) cannot been inferred from the small height of blisters as measured on the sample surface (Fig. 4b). 


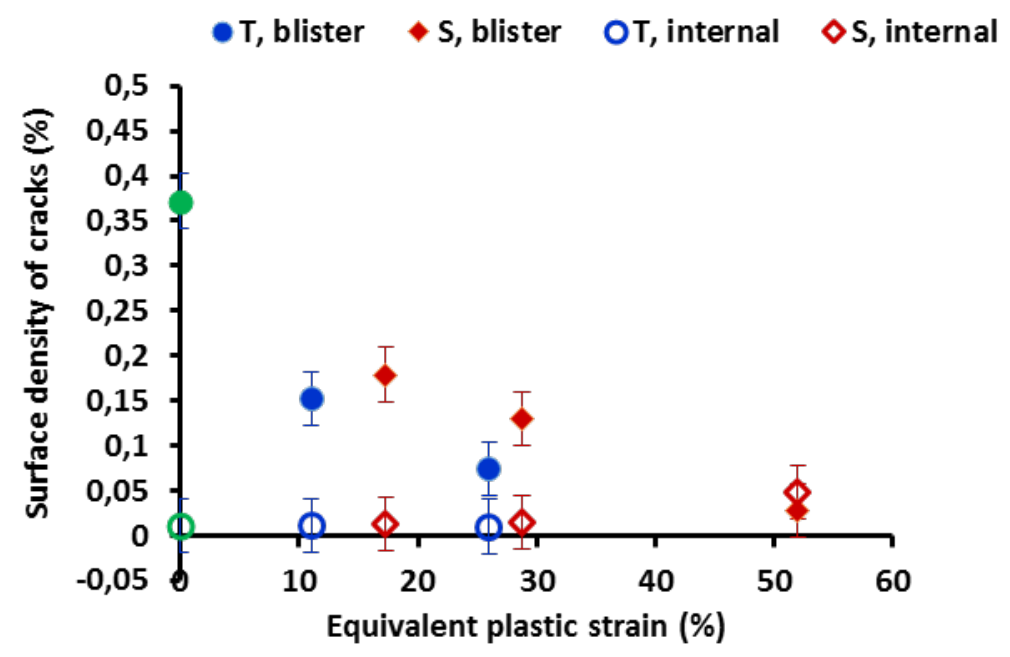

(a)

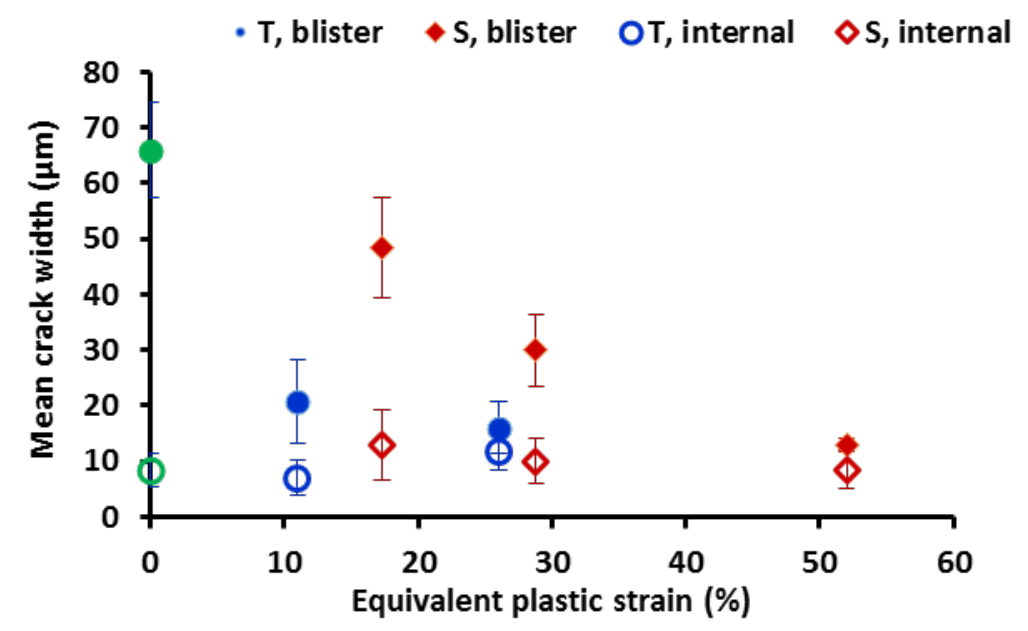

(b)

Fig. 8. Evolution with equivalent plastic strain of (a) the surface density and (b) mean crack opening displacement of hydrogen induced cracks observed in (RD, ND) sections after cathodic charging of tensile (T) or shear (S) prestrained samples. Full symbols refer to cracks under blisters and open ones to internal cracks. Green points refer to initial state (I-H).

\section{Discussion}

\subsection{Hydrogen induced cracking and blistering on the initial state}

From the above reported results, the hydrogen induced damage on the Armco iron in the initial state consists in blisters emerging from the sample surface, and which are in most cases correlated with cracks observed in perpendicular sections. Variations in crack size and crack path are observed at the grain scale, however from a global point of view, the cracks sets roughly follows curvilinear path under blisters, and often ending at the sample surface. In other words, the hydrogen induced damage is mainly linked to the surface or subsurface 
damage, contrary to the so-called "internal cracking" as found in various steels sheets, with cracks along the rolling direction at mid-thickness [19] without any evidence of surface emergence. This suggests on annealed single phase material a tendency for hydrogen concentration once blister nucleus begins to form (for example by void coalescence such as in Ren mechanism) since no other traps are present, leading to large open cracks whereas for stronger materials, both trap sites and local hardening avoid crack opening. In some cases residual stresses gradients through the material thickness due to previous processing could help crack initiation at mid-thickness, especially if theses gradients are symmetric with respect to the mid-plane.

The general aspect of the blisters observed in the present study are qualitatively consistent with available studies in the literature for non-deformed pure iron [14, 19-21], despite the limitations of precise comparisons due to the differences in charging conditions. The nature of electrolyte, the charging time and the current density influence the blister occurrence, as showed in Escobar study [19]. Blister size of around $50 \mu \mathrm{m}$ is suggested from Ren observations [20] in iron charged for $12 \mathrm{~h}$ with a $1 \mathrm{~mA} / \mathrm{cm}^{2}$ current density. For an arsenicpoisoned electrolyte, the average size of blisters analyzed from SEM images by Escobar [19] is ranging from 200 to $560 \mu \mathrm{m}$ after $1 \mathrm{~h}$ with a $10 \mathrm{~mA} / \mathrm{cm}^{2}$ current density, and for the same current density mean blister size of $115 \mu \mathrm{m}$ was found by Tiegel et al. [21] on a large grained high purity iron. These values are consistent with the present SEM observations (Fig. 5a) even if at a more macroscopic scale, the average size is considerably higher (Fig. 4a) and larger than the grain size.

It is noticed that the available picture of a cracked blister in Escobar work [19] shows cracks on the blister apex, whereas in the present observations cracks are mainly found on the blisters slopes, or at the interface between the surrounded surface (Fig. 5-6). If significant, this fact is not straightforward explainable and may be linked to the local stress state. The surface roughness may also contribute to local differences, and polished surface was shown to favor blister density [19]. In the present case, as electopolishing was performed before cathodic charging, the observed blisters exhibit marked slip lines evoking plastic straining due to the material bulging during the blister formation, which is consistent with the steps - associated to the underneath crack advance - and corresponding TEM observations of plasticity features in a recent study [21]. These authors also pointed out the very flat top of the blisters, observed after mechanical polishing with high grit paper grade, which seems less marked in the present observations. The local morphology of blisters is then expected to depend both on the material and on the surface conditions.

\subsection{Effect of plastic strain on the hydrogen induced cracking and blistering}

The present results clearly show the decrease of the blister density, of the size of the blisters and of the related cracks with increasing plastic strain (Fig. 3, 4, 8) in tensile or shear mode up to $50 \%$ equivalent strain. Meanwhile, some evidence of internal damage disconnected from blister formation is progressively seen, and is predominant in the highest deformed samples. It can be noticed that some quantitative results differ from tensile or shear deformation mode for the same equivalent prestrain values, as noticed by surfometry (see Fig. 4) and by quantitative SEM pictures analysis of cracks (see Fig. 8). This suggests the influence of the local 
deformation mechanisms and of the subsequent dislocation patterning, especially for high prestrain, on the hydrogen induced cracks.

Hydrogen trapping by dislocations is an important mechanism in hydrogen transport [23, 28, 29]. Kumnick and Johnson [30] reported from permeation tests a great increase of the trap density on Armco iron with plastic deformation at room temperature, from $10^{20} \mathrm{~m}^{-3}$ for the annealing iron up to $10^{23} \mathrm{~m}^{-3}$ for the strongly deformed iron up to $60 \%$ cold-working. Meanwhile, trapping is expected to reduce the apparent hydrogen diffusion coefficient [28, 29]. From the results of Kiuchi [28], the diffusivity ratio between cold-worked and annealed iron may be estimated to around $10^{-2}$. Accounting for this value in a rough estimation of the diffusion length by $(\mathrm{Dt})^{1 / 2}$, as used by other authors [31], where $\mathrm{D}$ is the diffusion coefficient (with value $1.27 \times 10^{-8} \mathrm{~m}^{2} / \mathrm{s}$ for non-deformed iron [32]) and the diffusion time $(\mathrm{t}=24 \mathrm{~h})$, leads to length value about $3 \mathrm{~mm}$, which is far larger than the sample thickness. Hydrogen is then expected to be able to cross the whole sample thickness, permitting the development of internal cracking in the deformed samples. Results on the effect of prestraining on HIC on iron are scarce, and no study concern shear loading. Hydrogen-induced cracking of plastically twisted iron was investigated by [33] and trans or intragranular cracking was observed, but as cathodic charging and twist testing was simultaneous, the results were not comparable with the present results despite the achievement of high shear strain values. From TDS of cold drawn iron wires the importance of desorption from dislocations with increasing strain was evidenced by [34] on ferritic steels, which suggests possible difference in hydrogen crack initiation mechanisms in deformed material, but results may be controversial. A study on a pipeline steel in sour environments [35] suggests the change of hydrogen induced cracks mechanisms with cold-work around $30 \%$ strain. Another study on different pipe steels [31] show no significant effect of moderate tensile prestrain on HIC results. As pointed out by Escobar et al [19] extensive internal cracking is more common in high strength steels such as dual-phase, ferrite-bainite or TRIP steels than in pure iron. Concomitantly with material strengthening, variations in composition and microstructure affect the hydrogen-material interactions, and especially the density of trap sites. As a result, the effective diffusivity is reduced, and the increase of trap sites, if sufficiently spatially dispersed, is expected to prevent or delay crack or blister formation due to less probable hydrogen accumulation and recombination. In the present case, the increase of dislocation density through plastic strain provokes both the increase of strain hardening and of the probability of hydrogen trapping on dislocations. Even if dislocations may locally contribute to lattice disorder and vacancies formation favorable to blister nuclei, the hydrogen pressure threshold for blister growth, accompanied by extra plastic strain, should be higher to overcome the effect of strainhardening in the prestrained samples. This may explain the present results showing that higher plastic strain before cathodic charging contributes to reduce blistering and crack opening (as seen in Fig. 8b) of the hydrogen induced cracks, for the same hydrogen entry amount in the samples.

\subsection{Simulation of the effect of loading mode on blistering initiation}

In section 3 was reported the observed differences of blistering with mechanical loading. For the same equivalent plastic strain, the equivalent stress is the same whatever the loading mode 
under the assumptions of isotropic hardening. However, the local stress state is clearly different and may differ from the mean global stress tensor, which influences the initiation and propagation of cracks and therefore the way the blister develops. This local stress state is not available experimentally, which has motivated FE simulations to account for the effect of loading mode on the void growth under internal pressure. Phenomenological approach was chosen here, with simple assumptions on material behavior and blister initiation mechanism.

Within the frameworks of continuum mechanics, blister initiation is assumed to result from voids growth due to hydrogen internal pressure. Numerical simulations are conducted to get (i) the evolution of a void size with increasing internal pressure and (ii) the material expansion due to voids growth, controlled by hydrogen diffusion and trapping by plasticity. The objective is to analyze the effect of the loading mode (either by tensile or shear, for the same equivalent plastic strain $\varepsilon=11 \%$ ) on this process and to compare with the experimental tendencies.

\subsubsection{Accounting of hydrogen trapping by dislocations and voids in transport equation}

To model hydrogen transport in a prestrained medium in which blistering is about to occur, the total hydrogen concentration $\mathrm{C}$ is considered as the sum of three parts, namely due to lattice diffusion $\mathrm{C}_{\mathrm{L}}$, to dislocation traps $\mathrm{C}^{\mathrm{T}}$ and to trapping by voids $\mathrm{C}_{\mathrm{T}}{ }^{\mathrm{b}}$.

The basis of the transport equation is adapted from literature, i.e, assuming a stress assisted hydrogen flux $\varphi[36]$

$$
\varphi=D_{L} \nabla C_{L}-D_{L} C_{L} \frac{V_{H}}{R T} \nabla P_{H}
$$

where $\mathrm{D}_{\mathrm{L}}$ is the diffusion coefficient of hydrogen, $\mathrm{P}_{\mathrm{H}}$ the hydrostatic stress, $\mathrm{V}_{\mathrm{H}}$ the partial hydrogen molar volume. The total hydrogen concentration $\mathrm{C}=\mathrm{C}_{\mathrm{L}}+\mathrm{C}_{\mathrm{T}}+\mathrm{C}_{\mathrm{T}}$ b obeys the equation

$$
\frac{\partial \mathrm{C}}{\partial \mathrm{t}}+\operatorname{div} \varphi=0
$$

Assuming equilibrium between diffusive and dislocation-trapped hydrogen $\mathrm{C}_{\mathrm{T}}$ evolution is given by $[23,32,37]$

$$
\frac{\partial \mathrm{C}_{\mathrm{T}}}{\partial \mathrm{t}}=\frac{\mathrm{C}_{\mathrm{T}}\left(1-\theta_{\mathrm{T}}\right)}{\mathrm{C}_{\mathrm{L}}} \frac{\partial \mathrm{C}_{\mathrm{L}}}{\partial \mathrm{t}}+\theta_{\mathrm{T}} \frac{\mathrm{dN}_{\mathrm{T}}}{\mathrm{d} \bar{\varepsilon}_{\mathrm{eq}}} \dot{\bar{\varepsilon}}_{\mathrm{eq}}
$$

$\theta_{T}\left(C_{T}=\theta_{T} N_{T}\right)$ is the trapped site occupancy and $N_{T}$, the trap density [32].

Void trapping is supposed to be directly linked to the recombination of diffusive hydrogen into hydrogen gas; this process is described under equilibrium by a Sievert law between $C_{L}$ and the internal pressure $\mathrm{P}$ in the void [38]

$$
\alpha \sqrt{P}=C_{L}
$$


$\alpha$ being a material constant, identified based on the literature for $\alpha$ iron: for $\mathrm{P}=1 \mathrm{~atm}$, $\mathrm{C}=\mathrm{C}_{0}=2.084 \times 10^{21}$ atom $/ \mathrm{m}^{3}=0.0034 \mathrm{~mol} \mathrm{H} / \mathrm{m} 3$ [32],[39], $\mathrm{P}$ is linked to the number $\mathrm{n}$ of $\mathrm{H}_{2}$ molecules through the perfect gas law

$$
P V=\frac{n}{N_{A}} R T
$$

$\mathrm{N}_{\mathrm{A}}$ being the Avogadro number and $\mathrm{V}$ the considered pore volume, leading to

$$
\mathrm{C}_{\mathrm{b}}^{\mathrm{T}}=2 \mathrm{nN}_{\mathrm{T}}^{\mathrm{b}}
$$

$\mathrm{N}_{\mathrm{T}}{ }^{\mathrm{b}}$ is here the void density. It is last assumed that void growth is only driven by internal pressure, so that

$$
\left\{\begin{array}{l}
P<P_{c}(r) \Rightarrow \dot{V}=0 \\
P=P_{c}(r) \text { and } \dot{P}>0 \Rightarrow \dot{V}>0
\end{array},\right.
$$

$\mathrm{r}$ being the equivalent radius of the void. $\mathrm{P}_{\mathrm{c}}(\mathrm{r})$ is characteristic function for void growth, to be identified.

From relations (4), (5), (6), one can obtain the evolution of $\mathrm{C}_{\mathrm{b}}^{\mathrm{T}}$ :

- for $\mathrm{P}<\mathrm{P}_{\mathrm{c}}(\mathrm{r})$ the differentiation of under constant volume leads to

$$
\frac{\partial C_{T}^{b}}{\partial t}=4 \frac{n}{P} \frac{C_{L}}{\alpha^{2}} N_{T}^{b} \frac{\partial C_{L}}{\partial t}
$$

- for $\mathrm{P}=\mathrm{P}_{\mathrm{c}}(\mathrm{r})$ the variation of $\mathrm{n}$ in the inflating void may be written

$$
d n=n\left(\frac{P_{C}{ }^{\prime}(r)}{P_{c}(r)}+\frac{3}{r}\right) d r=2 n \frac{C_{L}}{\alpha^{2} P^{\prime}{ }_{c}(r)}\left(\frac{P^{\prime}{ }_{c}(r)}{P_{c}(r)}+\frac{3}{r}\right) d C_{L}
$$

Considering $\mathrm{N}_{\mathrm{b}}$ voids with the same internal pressure in a volume $\mathrm{V}_{0}\left(\mathrm{~N}_{\mathrm{T}}{ }^{\mathrm{b}}=\mathrm{N}_{\mathrm{b}} / \mathrm{V}_{0}\right)$, the trap density change during volume increase $\mathrm{N}_{b} \mathrm{dV}$ is (assuming than $\mathrm{N}_{\mathrm{b}}$ remains unchanged with time)

$$
d N_{T}^{b}=-\left(N_{T}^{b}\right)^{2} d V
$$

The trapped concentration evolution is consequently

$$
d C_{T}^{b}=2 d n N_{T}^{b}+2 n d N_{T}^{b}
$$

which leads to

$$
\frac{\partial C_{T}^{b}}{\partial t}=4 n N_{T}^{b}\left(\frac{P^{\prime}(r)}{P_{c}(r)}+\frac{3}{r}-3 N_{T}^{b} \frac{V}{r}\right) \frac{C_{L}}{\alpha^{2} P^{\prime}{ }_{c}(r)} \frac{\partial C_{L}}{\partial t}
$$

Last, the volumetric strain induced by the voids growth is 


$$
\varepsilon_{t h}=\frac{N_{b} d V}{V_{0}}=N_{T}^{b} d V
$$

The hydrogen transport equation (2) accounting for (3), (7), (8), (12) has been implemented in Abaqus software adapting several user subroutines used in previous works [40] [41]. The material expansion due to void growth has been added using an UEXPAN subroutine.

Hydrogen related parameters for iron in equations (1) and (3) have been taken from literature [37], including the evolution of $\mathrm{N}_{T}$ with plastic strain. The only extra function $\mathrm{P}_{c}(\mathrm{r})$ has been obtained by mechanical cell computations as explained below.

\subsubsection{Evolution of void size with internal pressure}

To numerically create a void in a prestrained material, the mechanical loading is applied to a computational cell composed of an inclusion embedded in an elastic-plastic matrix. The cell is first prestrained up to a given macroscopic strain, then unloaded. The inclusion is then removed, and an increasing pressure (normal stress) is applied on the newly created surfaces. The evolution of the void volume (assuming an ellipsoidal shape) with internal pressure is extracted from the finite element results.

By symmetry one half of the cubic cell was modeled, with dimensions $20 \times 20 \times 10 \mu \mathrm{m}^{3}$. Periodic boundary conditions were applied on the lateral cell faces [42]. Prestrain was controlled by displacement conditions on top and bottom faces, for the overall plastic strain values of Fig. 4a.

The radius of the initial inclusion was $1.5 \mu \mathrm{m}$, which is consistent with the typical pore size observed on blister fracture surface (as in Fig. 6b). The computations were made with an elastic inclusion with $100 \mathrm{GPa}$ as Young's modulus and 0.3 as Poisson ratio, values for classical inclusions in iron such as manganese sulfides [43].

The iron matrix is isotropic elastic-plastic, with $200 \mathrm{GPa}$ Young's modulus. Plasticity is described with von Mises yield potential and isotropic hardening. From the stress-strain curves obtained in uniaxial tension, a Voce-type hardening law was identified for iron:

$$
\sigma_{Y}=A+B\left(1-e^{-C \bar{\varepsilon}}\right)
$$

with $\mathrm{A}=209 \mathrm{MPa}, \mathrm{B}=181.5 \mathrm{MPa}, \mathrm{C}=5.7, \sigma_{Y}$ is the von Mises stress and $\bar{\varepsilon}$ the equivalent plastic strain.

The Fig. 9 shows the plastic strain field around the void for $\bar{\varepsilon}=11 \%$ prestrain, by tension or by shear, for the maximum applied internal pressure. It can be noticed the effect of prestrain loading mode on the plastic strain distribution around the void. 


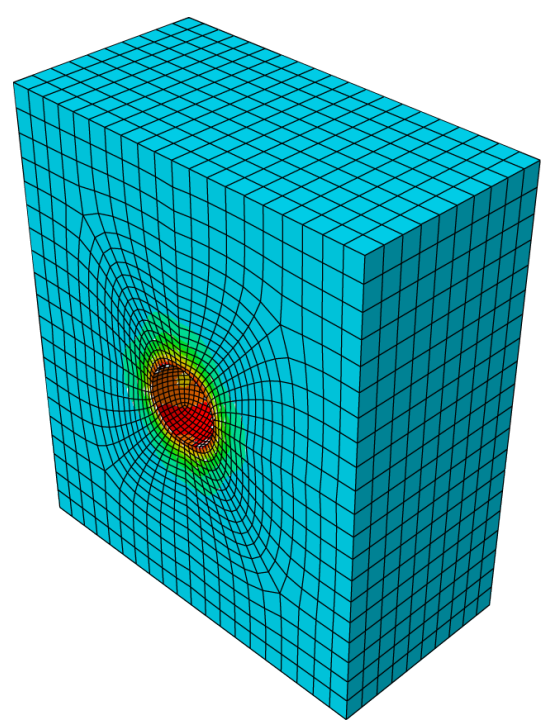

(a) tension

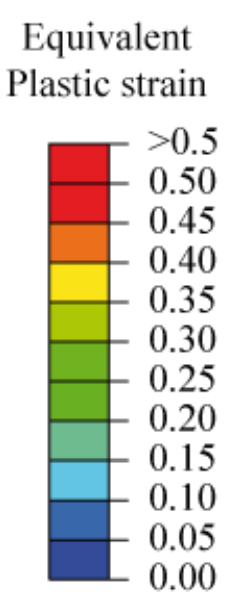

Fig. 9. Plastic strain field around the void for the maximum applied internal pressure (corresponding to saturation values in Fig. 14) after prestrain $\bar{\varepsilon}=11 \%$ by (a) tensile and (b) shear loading.

The evolution of the volume void with the applied internal pressure is plotted on Fig. 10 for all considered configurations.

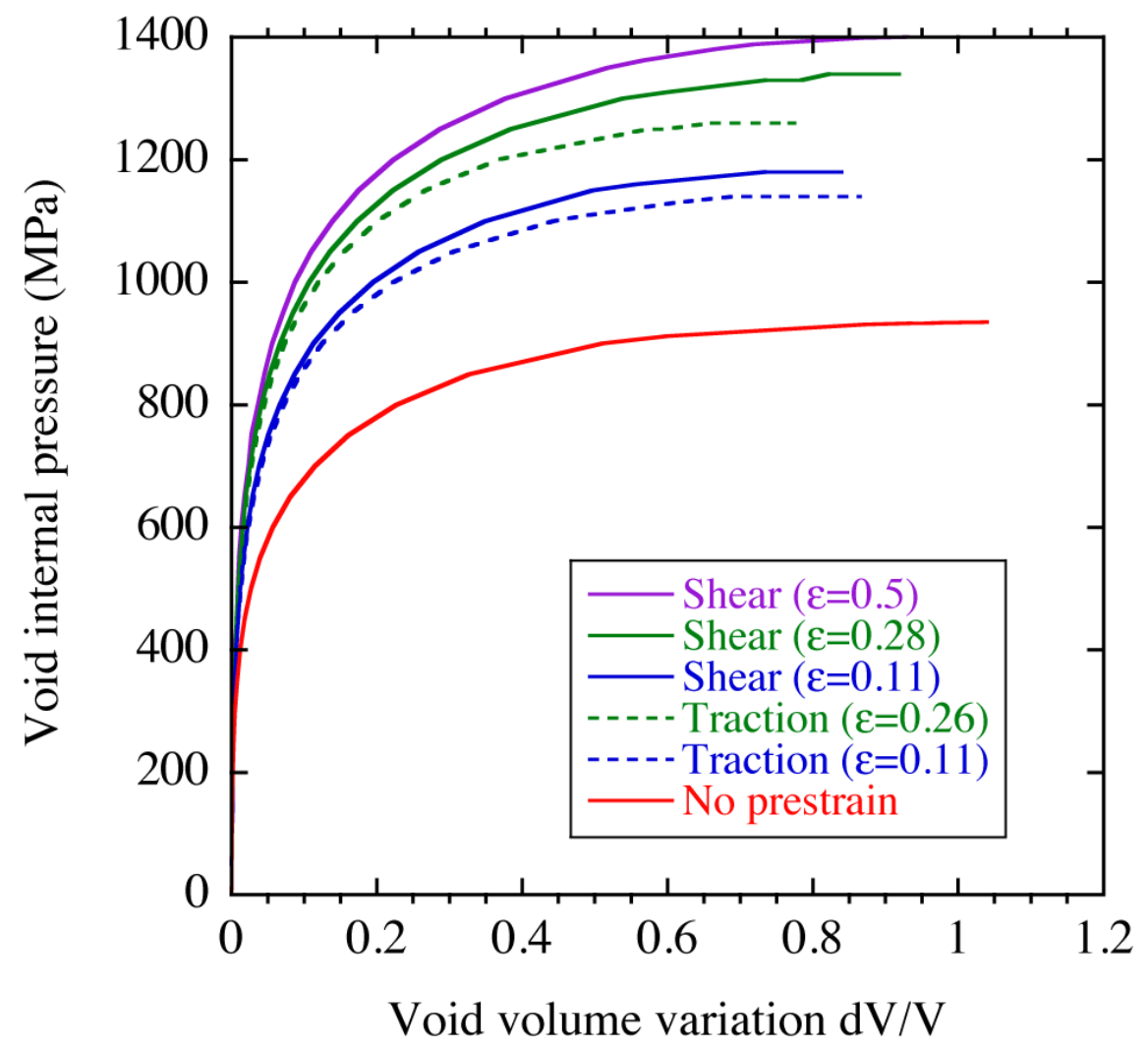

Fig. 10. Effect of the prestraining mode on the internal pressure evolution in a void with its relative volume change.

These results show that to reach a given void volume increase, the larger the prestrain, the higher the internal pressure. Furthermore, for a given volume change and a given prestrain, a 
higher pressure is needed for shear loading than for tension. It has been checked that the same conclusions are obtained for similar computations using initially an iron-made inclusion or a void, with negligible variations on the internal pressure values.

The curves of Fig. 10 permit to relate the internal pressure $\mathrm{P}$ to the void volume $\mathrm{V}$ and therefore to the radius $\mathrm{r}$ of a sphere with same volume. The relation between $\mathrm{P}$ and $\mathrm{r}$ is postulated as $\mathrm{P}(\mathrm{r})=\mathrm{a}+\mathrm{b}\left(1-\exp \left(-\mathrm{c}\left(\mathrm{r}-\mathrm{r}_{0}\right)\right)\right.$. The $\mathrm{a}, \mathrm{b}$, c parameters were identified for the nonprestrained material $(\varepsilon=0)$, and for plastic prestrain $\bar{\varepsilon}=11 \%$ by uniaxial tension and $\bar{\varepsilon}=11 \%$ by simple shear.

$\mathrm{P}(\mathrm{r})$ may be considered as the critical pressure $\mathrm{P}_{c}(\mathrm{r})$ for growth of a spherical void of radius $\mathrm{r}$, and was therefore used for the characteristic function (equation (7) in the application of the model proposed in the above section. Table 2 gives the retained values for $\mathrm{a}, \mathrm{b}$ and $\mathrm{c}$.

Table 2. Parameters identified from computations for the $P_{\mathbf{c}}$ function.

\begin{tabular}{|c|c|c|c|}
\hline Plastic prestrain & $\mathrm{a}(\mathrm{MPa})$ & $\mathrm{b}(\mathrm{MPa})$ & $\mathrm{c}\left(\mathrm{mm}^{-1}\right)$ \\
\hline$\varepsilon=0$ & 400 & 540 & 13000 \\
\hline $\bar{\varepsilon}=11 \%$ (tension) & 600 & 550 & 13500 \\
\hline $\bar{\varepsilon}=11 \%$ (shear) & 600 & 590 & 13000 \\
\hline
\end{tabular}

\subsubsection{Material expansion due to hydrogen induced voids growth}

To model pre-blistering on a surface, a continuous distribution of void nuclei is applied in a hemi-spherical zone of radius $12.25 \mu \mathrm{m}$ of a parallelepipedic iron sample of dimensions $50 \times 50 \times 25 \mu \mathrm{m}^{3}$. The distribution is defined as $N_{T}^{b}(r)=N_{\max }\left(1+\cos \left(2 \pi \frac{r}{r_{\max }}\right) / 2\right.$ for $\mathrm{r}_{0}<\mathrm{r}<\mathrm{r}_{\max }$ with $\mathrm{r}_{0}=1.5 \mu \mathrm{m}$ and $\mathrm{r}_{\max }=25 \mu \mathrm{m}$ ensuring blister development from the center of the hemi-sphere.

Each nucleus leads to a void which growth is controlled by hydrogen transport in the sample through the model presented in 4.3.1, provided the $\mathrm{P}_{\mathrm{c}}(\mathrm{r})$ function identified in 4.3.2. 


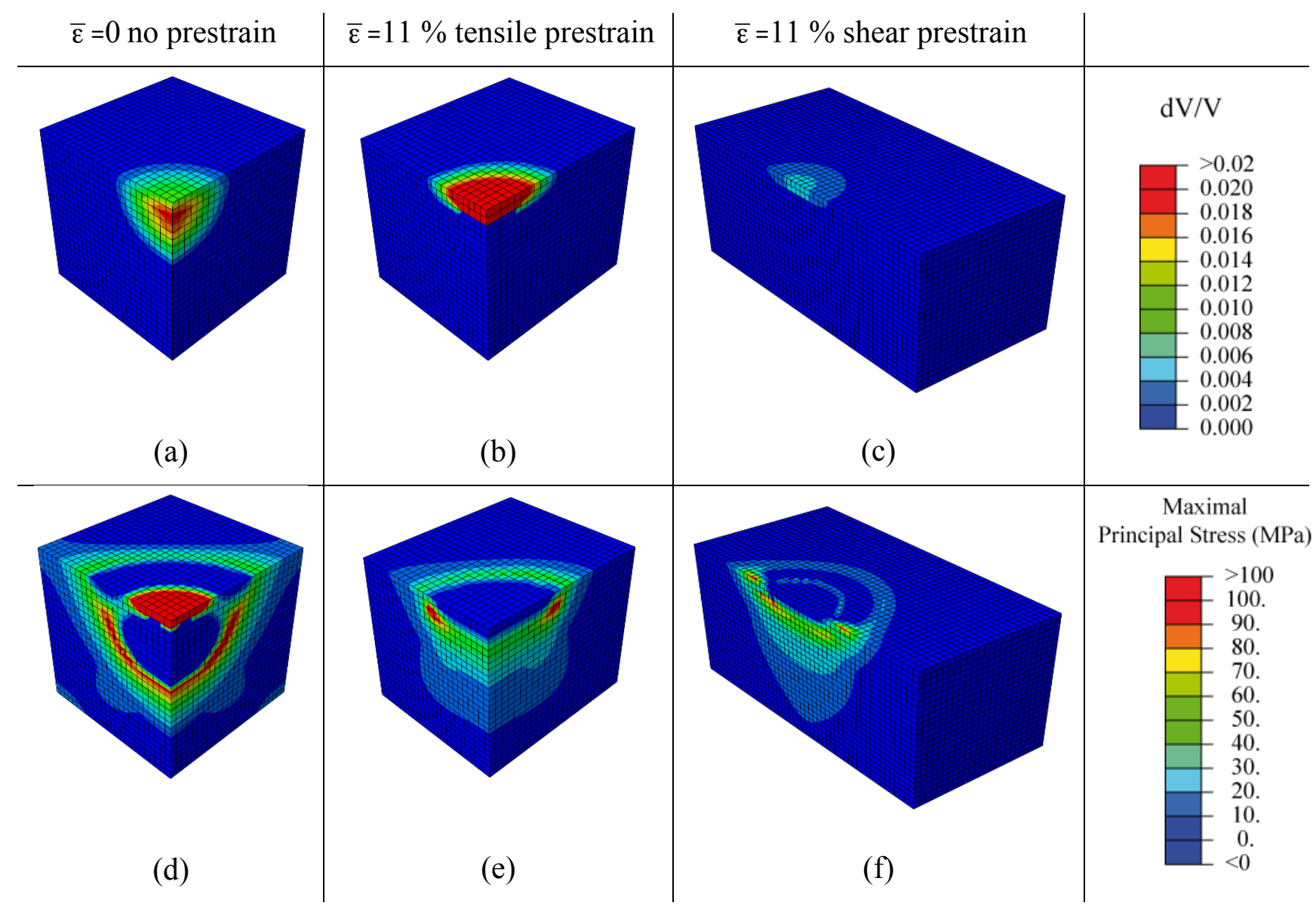

Fig. 11. Material expansion (a-c) and maximal principal stress field (d-f) at the end of computations for the studied configurations.

First mechanical prestraining is applied in the same way than for the computational cell in 4.2. Then hydrogen concentration is applied on the top surface, with value $0.38 \mathrm{~mol} \mathrm{H} / \mathrm{m}^{3}$. This value was chosen to correspond to internal pressure value close to saturation (ie permitting void maximal expansion) according to results of section 4.3.2. The computation is controlled by the applied internal hydrogen pressure $\mathrm{P}$ increase in voids.

The overall result of the voids growth is material expansion, computed as $\varepsilon_{\mathrm{th}}$, and development of stresses, which are shown in Fig. 11.

After hydrogen exposure, whether prestrained or not, the material inflates due to multiple voids growth, leading to a pre-blister configuration (the whole blister appears after a crack development bellow the inflating volume). At the center of the void nuclei area, the computation shows that the ratio of the pre-blister height for $11 \%$ prestrained material to the height for non-deformed material is 0.12 for tensile prestrain and 0.10 for shear one. These differences arise from the variation in the $\mathrm{P}_{c}(\mathrm{r})$ function for the three studied cases. As a consequence, void growth and material expansion are reduced in case of plastic prestrain, especially in the case of shear. This tendency, furthermore, is emphasized by the hydrogen transport process, which is affected (slowed) by the trapping by dislocations. Qualitatively, the simulated pre-blister heights order correlate with the experimental ones (Fig. 4), while being far in term of quantitative values. 
The final blister height, however, is mainly due to the crack development and crack opening, as it can be observed through Fig. 4 and 8 comparison. The conditions for a crack initiation and development around the inflating area appear consequently to be the key feature for the final blister topology analysis. Hydrogen embrittlement is related to brittle cracking, then the mechanical conditions of crack initiation are expected to be sensitive to the maximal principal stress field. The comparison of Fig. $11 \mathrm{~d}$-f suggests, at the attainment of maximum pressure in voids, higher stresses in non-deformed material compared to prestrained material, and then earlier cracking and more open cracks.

Finally these computations have shown plastic prestrain mode may have an important influence on the blistering process, through the pre-blistering formation and the void nucleation process. The present model is a first step for the description of blister formation, Modeling the complete process of blistering involves to account both for crack propagation and for microstructural features, which needs further developements.

\section{Conclusions}

Cathodic charging on prestrained Armco iron has been performed to investigate the effect of plastic strain on the hydrogen-induced cracks and blisters. The main results are:

- Plastic straining before cathodic charging leads to decrease the size and the surface density of blisters at the samples surface. Meanwhile the underneath cracks opening is less important. The corresponding geometric features measured by surfometry and image analysis are useful data in view of finite element simulations of blistering from phenomenological approach (work in progress). For the same equivalent plastic strain, blistering is less important after shear test compared with tensile test;

- The effect of prestrain loading on pre-blistering formation has been modeled by finite element simulations of hydrogen transport accounting for both stress-assisted diffusion and trapping by dislocations and by voids, provided a phenomenological void growth law under internal pressure. Results show consistent tendencies with experimental measurements, underlying the importance of the plastic strain development around voids and its influence of void growth in the blister formation process.

\section{References}

1. Bernstein, I.M., The Role of Hydrogen in the Embrittlement of Iron and Steel. Materials Science and Engineering, 1970. 6(1970): p. 1-19.

2. Cotterill, P., The hydrogen embrittlement of metals. Progress in Materials Science, 1961. 9(4): p. 205-250.

3. Elazzizi, A., et al., The master failure curve of pipe steels and crack paths in connection with hydrogen embrittlement. International Journal of Hydrogen Energy, 2015. 40(5): p. 2295-2302. 
4. Juan, A., et al., The electronic structure and bonding of a $H-H$ pair in the vicinity of a BCC Fe bulk vacancy. International Journal of Hydrogen Energy, 2003. 28(9): p. 9951004.

5. $\quad \mathrm{Li}, \mathrm{S}$., et al., The interaction of dislocations and hydrogen-vacancy complexes and its importance for deformation-induced proto nano-voids formation in $\alpha-F e$. International Journal of Plasticity, 2015.

6. Djukic, M.B., et al., Hydrogen damage of steels: A case study and hydrogen embrittlement model. Engineering Failure Analysis, 2015.

7. Takano, N., Y. Yokka, and F. Terasaki, The effect of copper precipitation on hydrogen embrittlement in iron. Materials Science and Engineering: A, 2004. 387-389: p. 428432.

8. Suzhi Li, Y.L., Yu-Chieh Lo et al., The interaction of dislocations and hydrogenvacancy complexes and its importance for deformation-induced proto nano-voids formation in $\alpha-F e$. International Journal of Plasticity, 2015. 74: p. 175-191.

9. Robertson, I.M., The effect of hydrogen on dislocation dynamics. Engineering Fracture Mechanics, 1999. 64: p. 649-673.

10. Kimura, A. and H.K. Birnbaum, Hydrogen induced grain boundary fracture in high purity nickel and its alloys - Enhanced hydrogen diffusion along grain boundaries. Acta Metall., 1988. 36(3): p. 757-766.

11. Alvaro, A., V. Olden, and O.M. Akselsen, 3D cohesive modelling of hydrogen embrittlement in the heat affected zone of an X70 pipeline steel - Part II. International Journal of Hydrogen Energy, 2014. 39(7): p. 3528-3541.

12. Ilin, D.N., et al., Simulation of hydrogen diffusion affected by stress-strain heterogeneity in polycrystalline stainless steel. International Journal of Hydrogen Energy, 2014. 39(5): p. 2418-2422.

13. Condon, J.B. and T. Schober, Hydrogen bubbles in metals. Journal of Nuclear Materials, 1993. 207: p. 1-24.

14. Griesche, A., et al., Three-dimensional imaging of hydrogen blister in iron with neutron tomography. Acta Materialia, 2014. 78(0): p. 14-22.

15. Hoshihira, T., T. Otsuka, and T. Tanabe, Visualization of hydrogen distribution around blisters by tritium radio-luminography. Journal of Nuclear Materials, 2009. 386-388: p. 776-779.

16. Ren, X., et al., The effects of inclusions and second phase particles on hydrogeninduced blistering in iron. Materials Chemistry and Physics, 2008. 107(2-3): p. 231235.

17. Ravi, K., V. Ramaswamy, and T.K.G. Namboodhiri, Hydrogen Sulphide Resistance of High Sulphur Microalloyed Steels. Materials Science and Engineering, 1990. A129: p. 87-97.

18. A.V. Nikitina, et al., Blister formation on $13 \mathrm{Cr} 2 \mathrm{MoNbVB}$ ferritic-martensitic steel exposed to hydrogen plasma. Journal of Nuclear Materials, 2016. 478: p. 26-31.

19. Pérez Escobar, D., et al., Internal and surface damage of multiphase steels and pure iron after electrochemical hydrogen charging. Corrosion Science, 2011. 53(10): p. 3166-3176.

20. Ren, X.C., et al., A Nucleation Mechanism of Hydrogen Blister in Metals and Alloys. Metallurgical and Materials Transactions A, 2007. 39(1): p. 87-97.

21. Tiegel, M.C., et al., Crack and blister initiation and growth in purified iron due to hydrogen loading. Acta Materialia, 2016. 115: p. 24-34.

22. Saleh, A.A., et al., Investigation of the effect of electrolytic hydrogen charging of X70 steel: II. Microstructural and cristallographic analyses of the formation of hydrogen 
induced cracks and blisters. International Journal of Hydrogen Energy, 2016. xxx: p. $1-12$.

23. Oriani, R.A., The diffusion and trapping of hydrogen in steel. Acta Metallurgica, 1970. 18(january 1970): p. 147-157.

24. Hwang, C. and I.M. Bernstein, Dislocation transport of hydrogen in iron single crystals. Acta Metall., 1986. 34(6): p. 1001-1010.

25. Bouvier, S., et al., Simple shear tests: Experimental techniques and characterization of the plastic anisotropy of rolled sheets at large strains. Journal of Materials Processing Technology, 2006. 172(1): p. 96-103.

26. Bouvier, S., et al., Characterization of the strain-induced plastic anisotropy of rolled sheets by using sequences of simple shear and uniaxial tensile tests. Journal of Materials Processing Technology, 2006. 174(1-3): p. 115-126.

27. ISO, ISO 25178-2, Geometrical Product Specification (GPS) - Surface texture: Areal Part 2: Terms, definitions and surface texture parameters, 2012, Geometrical Product Specification (GPS) - Surface texture: Areal - Part 2: Terms, definitions and surface texture parameters.

28. Kiuchi, K. and R.B. McLellan, The solubility and diffusivity of hydrogen in wellannealed and deformed iron. Acta Metall., 1983. 31(7): p. 961-984.

29. Brass, A.M. and J. Chene, Influence of deformation on the hydrogen behavior in iron and nickel base alloys: a review of experimental data. Materials Science and Engineering A, 1998. 242: p. 210-221.

30. Kumnick, A.J. and H.H. Johnson, Deep trapping states for hydrogen in deformed iron. Acta Metallurgica, 1980. 28: p. 33-39.

31. Angus, G.R., et al. Characterization of an Electronlytic Charging Method to Assess Hydrogen-Induced Damage in Pipeline Steels. in SteelyHydrogen 2014 Conference. 2014. Ghent, 5-7 May 2014.

32. Sofronis, P. and R.M. McMeeking, Numerical analysis of hydrogen transport near a blunting crack tip. J. Mech. Phys. Solids, 1989. 37(3): p. 317-350.

33. Lunarska, E., Hydrogen-induced cracking of plastically twisted iron. Scripta Metallurgica, 1981. 15: p. 1149-1152.

34. Nagumo, M., K. Takai, and N. Okuda, Nature of hydrogen trapping sites in steels induced by plastic deformation. Journal of Alloys and Compounds, 1999. 293-295(0): p. $310-316$.

35. JD., H.H.a.S., Cold work effects on sulfide stress cracking of pipeline steel exposed to sour environments Corrosion Science, 1993. 34: p. 61-78.

36. Li, J.C.M., R.A. Oriani, and L. Darken, The Thermodynamics of Stressed Solids. Zeitschrift Für Physikalische Chemie. International journal of research in physical chemistry and chemical physics, 1966. 45(3:5): p. 271-290.

37. Krom, A.H.M., R.W.J. Koers, and A. Bakker, Hydrogen transport near a blunting crack tip. Journal of the Mechanics and Physics of Solids, 1999. 47(4): p. 971-992.

38. Rudzinski, W. and W. Plazinski, Theoretical Description of the Kinetics of Solute Adsorption at Heterogeneous Solid/Solution Interfaces: on the Possibility of Distinguishing Between the Diffusional and the Surface Reaction Kinetics Models. Applied Surface Science, 2007. 253(13): p. 5827-40.

39. Taha, A. and P. Sofronis, A micromechanics approach to the study of hydrogen transport and embrittlement. Engineering Fracture Mechanics, 2001. 68(6): p. 803837.

40. NGuyen, T.H., Développement d'outils numériques pour la prise en compte du couplage hydrogène-plasticité dans un code éléments finis; application à l'essai de 
pliage en $U$, in LSPM-CNRS2014, Université Paris 13, Paris Sorbonne Cité: Université Paris 13, Villetaneuse.

41. Charles, Y., N. T.H., and M. Gasperini, FE simulation of the influence of plastic strain on hydrogen distribution during an U-bend test. International Journal of Mechanical Sciences, 2017.

42. Charles, Y., et al., Modelling the competition between interface debonding and particle fracture using a plastic strain dependent cohesive zone. Engineering Fracture Mechanics, 2010. 77(4): p. 705-718.

43. Murakami, Y., Metal fatigue: effects of small defects and nonmetallic inclusions2002: Elsevier. 